\title{
Indisciplina e discurso pedagógico: efeitos de sentidos diversos em confronto
}

\author{
Indiscipline and pedagogical discourse: effects of different senses in confrontation \\ Indisciplina y discurso pedagógico: efectos de sentidos diversos en la confrontación
}

\author{
REginA MARIA VARINI MUTTI*
}

\begin{abstract}
RESUMO - Este estudo, situando o discurso pedagógico, propõe-se a evidenciar efeitos de sentidos sobre indisciplina na sala de aula. Ancorado no referencial da análise de discurso de linha pêcheuxtiana, enfoca as posições de sujeito-estagiário e de sujeito-professor efetivo na escola, no Ensino Fundamental e no Ensino Médio. O corpus analítico é heterogêneo, constituindo-se de textos produzidos pelos estagiários da licenciatura em Letras sobre a experiência como regentes de classe na escola e de entrevistas de professores de português, representando escolas de regiões distintas. $\mathrm{O}$ estudo das designações discursivas empreendido destaca que as palavras, no uso, estão sujeitas a reformulações do sentido, de acordo com a historicidade dos sujeitos. Diversos efeitos de sentidos foram apreendidos mediante a análise, mostrando o confronto de posições discursivas diversas e a busca, pelo professor, da superação das dificuldades encontradas. Sugere-se que o tema seja objetivado explicitamente nos cursos de formação na licenciatura e de formação continuada.
\end{abstract}

Palavras-chave - Discurso pedagógico. Efeitos de sentido. Indisciplina. Sala de aula. Estagiário. Professor.

\begin{abstract}
This study is proposed to show effects of meanings on indiscipline in classroom, regarding the pedagogical discourse. Anchored in the Pêcheuxtian Discourse Analysis, the study emphasizes the subject-trainee positions and subject-effective school teacher, in elementary school and high school. The analytical corpus is heterogeneous, built of texts produced by trainees of Portuguese Language degree that reported their experience as Regents of class in school. Interviews of Portuguese teachers were also used, representing schools of different regions. The study of the discursive designation points out that the words in use are subject to reformulations of meaning, according to the historicity of the subject. Several effects of senses were produced by the analysis, showing the confrontation of different discursive positions and the pursuit by teachers of a resolution for theirs difficulties. It is suggested that the theme need to be explicitly treated in degree and continuing education.
\end{abstract}

Keywords - Pedagogical discourse. Meaning effects. Indiscipline. Classroom. Trainee. Teacher.

RESUMEN - Este estudio, situando el discurso pedagógico, se propone mostrar los efectos de sentidos acerca de la indisciplina en el aula. Anclado en el marco del análisis del discurso de la línea "pêcheuxtiana", se centra en las posiciones de sujeto-pasante y de sujeto-profesor, en la escuela primaria y en la escuela secundaria. El corpus analítico es heterogéneo, constituyéndose de textos producidos por los pasantes del curso de letras sobre la experiencia como regentes de clase en la escuela y de entrevistas a los profesores de portugués, representando escuelas de diferentes regiones. El estudio de las asignaciones discursivas emprendido destaca que las palabras en el uso, están sujetas a la reformulaciones del sentido, de acuerdo con la historicidad del sujeto. Varios efectos de sentido fueron aprehendidos por el análisis, lo que muestra el confronto de posiciones discursivas diversas y la búsqueda, por parte del profesor, de las dificultades encontradas; se sugiere que el tema sea objetivado de manera explícita en los cursos de formación de letras y en la formación continua.

Palabras clave - Discurso pedagógico. Efectos de sentido. Indisciplina. Sala de aula. Pasante. Profesor.

\footnotetext{
* Doutora em Linguística e Letras pela Pontifícia Universidade Católica do Rio Grande do Sul (Porto Alegre, RS, Brasil) e professora na Universidade Federal do Rio Grande do Sul (Porto Alegre, RS, Brasil). E-mail: <reginamutti@terra.com.br>. Agradeço a Claudia Landin Negreiros pela colaboração para o estabelecimento do corpus analítico e a Dóris Maria Luzzardi Fiss pela leitura criteriosa e sugestões feitas.
} 


\section{INTRODUÇÃO}

A investigação representada neste artigo, situando o discurso pedagógico, enfoca, num primeiro momento, a análise de efeitos de sentidos manifestados pelo sujeitoestagiário da licenciatura em português, em suas narrativas sobre a experiência de regência de classe na escola. ${ }^{1}$ Num segundo momento, a análise discursiva se desloca para a perspectiva do sujeito-professor de português já estabelecido profissionalmente, centrando-se em seus depoimentos sobre as suas práticas de ensino na sala de aula, obtidos em entrevistas orais, gravadas e transcritas.

Além dos fatores referentes às situações funcionais distintas, de estagiário e professor, e dos também distintos gêneros do discurso de onde foram extraídas as formulações para análise, relatos escritos e entrevistas orais, o corpus deste estudo é também heterogêneo pela descontinuidade temporal e diferenças espaciais e culturais que caracterizam a sua constituição. Enquanto os estagiários ministraram aulas em escolas da cidade de Porto Alegre e região metropolitana, no Estado do Rio Grande do Sul, os professores entrevistados lecionaram em escolas de um município do interior do Estado de Mato Grosso, que integra também escolas de localizações distantes entre si.

Desse modo, nesta pesquisa, encontram-se representadas condições diversificadas de efetivação da docência em sala de aula. O intervalo de cerca de uma década entre as formulações discursivas dos estagiários e dos professores que fazem parte deste estudo ${ }^{2}$ é outro fator diferencial. Somam-se, ainda, fatores relativos às diferenças culturais regionais, dado o afastamento geográfico das duas regiões brasileiras envolvidas e as condições diferentes de experiência quanto ao desempenho da docência. Em comum, o desafio da sala de aula, com o qual se depara o estagiário nos seus primeiros contatos com essa realidade. Esse desafio permanece, embora transformado pela ampliação da experiência, durante todo o tempo de exercício profissional. A cada turma nova assumida, e mesmo a cada dia em que o professor se reapresenta diante da classe, supõe-se a confirmação tácita de sua liderança na condução do trabalho pedagógico. Concerne ao trabalho do professor investir no relacionamento com a classe, favorável à efetivação do ensino e da aprendizagem, e isso passa pela constituição de uma base de interlocução consentida - e duradoura entre ele e seus alunos, durante todo o processo.

Sem pretender abranger a complexidade da conjuntura assinalada, este trabalho busca mostrar efeitos de sentidos sobre alguns dos enfrentamentos que caracterizam a regência de classe, referidos como indisciplina e outras designações afins. Desse modo, o estudo pretende dar alguma visibilidade ao interior da sala de aula presencial, chamando atenção às condições do exercício da docência. São questões antigas, revestidas de novos sentidos ou não, mas que mobilizam fortemente o professor. Conforme a perspectiva discursiva onde se ancora o estudo, formação implica modos de subjetivação, dinâmicos e singulares. Essa concepção abrange, pois, no caso deste estudo, tanto a formação na licenciatura quanto a formação permanente no exercício da profissão. Considera-se, segundo Pêcheux (1997b), as noções de estrutura e acontecimento, inscritas no uso da língua pelo sujeito que produz sentidos.

Em conformidade com o referencial da análise de discurso de tradição pêcheuxtiana, destacando inclusive a perspectiva desenvolvida por Orlandi (1999), os procedimentos analíticos destacam a relação entre o intradiscurso, nível das formulações discursivas pelas quais se materializa o discurso por meio da enunciação, e o interdiscurso, nível dos saberes, da memória, apontando ao enunciável do discurso. Cabe então ao sujeito-analista debruçar-se sobre o corpus da pesquisa, tendo em vista o funcionamento discursivo de marcas linguísticas, visando a mostrar efeitos de sentidos resultantes de seu gesto de interpretação. Ernst-Pereira e Mutti (2011, p. 818) salientam: "é sabido que não basta o propósito crítico, sociológico, para dar conta da especificidade da posição de analista de discurso; assim, se ao linguista, conforme coloca Authier-Revuz (2006), costuma atribuir-se o cuidado com a língua, ao analista de discurso caberia o cuidado com o discurso representado na língua".

Neste estudo, a marca linguística selecionada incidiu no uso de elementos lexicais pelos sujeitos; para a descrição desses empregos de palavras, recorreu-se à noção de designação discursiva. Essa noção indica que, enquanto o léxico é da ordem da língua, tendo, pois, um caráter estável, a designação é da ordem do discurso, abrindo-se a variações do sentido. Considera-se que uma mesma palavra ou sintagma da língua pode fazer referência a sentidos pertencentes a posições discursivas em confronto.

\section{A PRODUÇÃo DE SENTIDOS NO USO DA LÍNGUA}

As inquietações voltadas aos empregos da palavra disciplina/indisciplina na sala de aula que nos mobilizam, iniciadas em estudo anterior sobre a posição do sujeitoestagiário (MUTTI, 2003b), neste artigo aprofundam-se com o enfoque da perspectiva do sujeito-professor de português efetivo; a constituição do novo corpus passou a representar a produção de sentidos nessas duas posições de sujeito.

Em relação ao estagiário, entende-se que a produção de sentidos se constitui sob uma dupla influência: a de discursos do campo de conhecimentos específicos do seu 
curso e a de posições discursivas provenientes do campo da educação, apropriadas recentemente nos seus estudos na licenciatura. $\mathrm{O}$ estágio, como acontecimento, significa um lugar de passagem em que o estudante pode ver-se, mesmo que provisoriamente, como profissional. Consiste num espaço legitimado para pôr em xeque a viabilidade, diante da complexidade da prática, de discursos teóricos estudados na universidade. Na condição de acadêmico, será avaliado e então precisará demonstrar, em seus pronunciamentos, como foi o seu diálogo com os referenciais estudados.

No entanto, o contato com a escola também revira sentidos de vivências diversas, tradicionais ou não, relacionadas à escolaridade. Por um lado, supõe-se que o referencial acadêmico sobre a educação e o ensino de língua que constituiu na universidade é o ponto de apoio para compreender as situações complexas que se apresentam na prática do estágio. Sentindo-se mais ou menos apto à regência de uma classe, conta com a devida orientação institucional nessa passagem que, embora transitória, é desafiadora.

Ao serem aplicados às situações da prática, os saberes sofrerão questionamentos, aparecendo as possíveis lacunas. Os referenciais teóricos não são entendidos como prontos e acabados, segundo se depreende do artigo de Pêcheux (1997b) comentado por Mutti (2003a); desse modo, discursivamente, os sentidos das teorias movimentam-se, podendo renovar-se, ao serem apropriados pelos usuários. Entende-se que a produção textual do sujeito-estagiário, caracterizada como relatos de suas experiências, seja endereçada primordialmente a interlocutores do contexto acadêmico. Já em relação aos professores titulados, é natural que alguns dos impactos pertinentes ao estágio possam encontrar-se atenuados. Mas como os desafios da docência não cessam de se apresentar, e deles fazem parte as questões de disciplina, mesmo após sucessivos anos de prática, os professores também se referem à indisciplina dos alunos como um fator desgastante, embora também capaz de levar à produção de novos sentidos. Nas enunciações falaram também de interesse/desinteresse, respeito, falta de educação, falta de perspectivas de continuidade dos estudos, falta de apoio das famílias ao professor, trabalho massacrante.

Considerando uma perspectiva polissêmica, indicamos os efeitos de sentidos produzidos pelos sujeitos. Os estagiários, diante da possibilidade de se desestabilizarem pela presença da temida indisciplina, focalizaram-na como objeto de suas enunciações em seus textos. Tomando disciplina como objeto do discurso, criaram belos textos sobre os sentidos que a disciplina e a indisciplina assumem no discurso pedagógico, reformulando esses sentidos; assim, efetivaram uma aproximação maior com esse problema, diminuindo-o, talvez, pelas vias da racionalidade e da estética na escrita. Ao tematizar a indisciplina, para traduzi-la em outras palavras, repensaram os lugares de professor, de aluno, bem como a sala de aula, o currículo, o plano de ensino. O sentido ligado à experiência ganha seu espaço na memória discursiva pedagógica (MUTTI, 2005).

Os efeitos de sentido a respeito da condição de estagiário - e de professor - parecem condizentes com o propósito de explicitar algo difícil de contornar em sala de aula, não somente de origem estritamente pedagógica, mas que influi na efetivação do objetivo pedagógico do professor. Entende-se que significados tradicionais das palavras conhecidas, muito arraigados, figuram na memória discursiva dos sujeitos como se estivessem de plantão, prontos para caírem no intradiscurso, quando o sujeito enuncia para significar uma dada realidade. Para os estagiários, disciplina seria uma dessas palavras ameaçadoras, prontas para o uso no momento em que têm de assumir uma classe.

Mas a cada enunciação há também a possibilidade de questionar a palavra e talvez não proferi-la como se esta coincidisse exatamente com o que se deseja nomear. Pode haver a interposição de outras posições discursivas, com sentidos outros. Esse movimento condiz com a forma sempre singular de o sujeito produzir sentidos por meio das palavras de sua língua, pois, como as situações de uso das palavras são diferentes, as nomeações não são iguais. Como o comprovam os estudos de Authier-Revuz (1998) a respeito da heterogeneidade enunciativa, não há uma coincidência exata da relação entre o objeto a ser nomeado e a nomeação feita.

Ao modo como indica Bahbha (1998), tratando das diferenças culturais inscritas na língua, os significados estabilizados das palavras escondem as condições da nomeação. As palavras contêm uma linha invisível que mantém apagada a posição subjetiva de onde parte a nomeação. Tornando-se estáveis, os signos linguísticos parecem não comportar a possibilidade de diferenças quanto ao estabelecimento do referente. Mesmo assim, podem tornar-se alvo de questionamento pelos sujeitos que se dispõem a não carregar meramente sentidos que não assumem como seus. Transformam-se assim os sentidos pela ação dos sujeitos.

Compreende-se que as palavras não servem propriamente para etiquetar os objetos do mundo, mas para constituí-los, discursivamente. Será que isso que ocorre na minha sala é indisciplina mesmo? Os sentidos das palavras são indissociáveis do seu uso pelos sujeitos na vida social. Conforme a perspectiva discursiva enfocada neste artigo, interessa a relação entre enunciações que comportam o emprego das palavras, destacando que se trata de acontecimentos de linguagem, pois "o agenciamento enunciativo específico da nomeação é 
elemento constitutivo da designação de um nome [...] no caso da relação entre designação e referência, o que se deve buscar é como um nome aparece referindo no texto em que ocorre" (GUIMARÃES, 2002, p. 27).

Segundo o autor citado, a historicidade da enunciação fica assim incluída nos estudos semânticos, distintamente da concepção de semântica como restrita à ordem da língua concebida como sistema abstrato. $\mathrm{O}$ autor propõe-se a definir um campo de trabalho semântico preocupado com o que "Saussure excluiu de seu objeto" (GUIMARÃES, 1995, p. 65), ao estabelecer a linguística como ciência. Levando em conta que o sentido das palavras é determinado pelas condições sócio-históricas de sua produção, busca mostrar como essas condições estão representadas no uso das palavras, dependendo, o sentido, dos lugares de interpretação.

Nos dicionários encontram-se inventariadas as acepções das palavras da língua que já estão legitimadas socialmente. Conforme Ferreira (1999, p. 689), disciplina remete a ensino, faz parte das condições de ensinar, constando tanto no discurso pedagógico quanto no militar, tal como é exemplificado. No entanto, podemos considerar que os sentidos das palavras se modificam a cada uso e, desse modo, nem todos os sentidos que são produzidos na vida concreta ficam registrados na memória discursiva, que é de natureza social. Alguns sentidos são considerados legítimos, ficam guardados no dicionário, na memória das áreas do conhecimento, outros não. Os dicionários, sendo também produções discursivas de sujeitos, não podem atingir completude e neutralidade em seus registros linguísticos.

A disciplina se destaca no discurso pedagógico; é uma condição, para o professor, de ministrar a aula e, para o aluno, de aprender os conteúdos curriculares ensinados. Escolarização não ocorre sem disciplinamento. O problema está em relação aos modos como se dão as relações entre os sujeitos envolvidos para que a disciplina ocorra. Os professores, os alunos, os pais, os diretores, os coordenadores pedagógicos compartilham a necessidade de que seja mantida a disciplina em sala de aula, mas recai sobre o professor a responsabilidade de que esta se efetive; dele é cobrado não deixar que comportamentos de indisciplina se instalem em sua classe.

Manter a disciplina passa a ser um trabalho adicional oneroso para o professor, pois é uma condição de infraestrutura para que a relação pedagógica, que supõe o triângulo básico professor-aluno-referente do ensino se efetive a contento. Mas uma harmonia plena não existe; a afinação dessas três pontas não será permanente, a disciplina na escola não se dá sem conflitos. Os problemas de disciplina, para além do desgaste dos sujeitos envolvidos, especialmente o professor, trazem perdas para a sociedade como um todo. Um estudo, na área sociológica, realizado por François Dubet (1977, p. 223), ressaltou que o comportamento dos jovens como alunos receptivos às propostas de ensino do professor não é algo natural. Não é espontaneamente que irão comportar-se como tal; por isso, a resistência ao professor, a hostilidade, inclusive, podem ocorrer com frequência, em decorrência dessa dificuldade de reconhecer a importância da escola. Não se preocupam em fingir que estão ouvindo para não fazer barulho e não perturbar o andamento das atividades, não têm pudor em ocupar-se com outras coisas durante a aula. $\mathrm{O}$ tempo para realização do ensino é relegado a apenas uma parte dos períodos de aula, já que grande parte desse tempo se destina às ações de pedir silêncio e organizar as condições para dar a aula. A indisciplina que se mostra na sala de aula suscita que se cogite de situações sociais graves, conforme enunciaram alguns professores, o que será mostrado no próximo subtítulo deste artigo. Tais enfrentamentos, e como lidar com eles, mereceriam enfoque específico nos cursos de licenciatura e de formação continuada dos professores.

A complexidade de problemas sociais mais amplos, desse modo, também está contida no amálgama de designações da palavra disciplina; não é raro que os referentes construídos pelos sujeitos a essa palavra sejam muito discrepantes, e que os professores na escola não tenham exigências equivalentes quanto à consideração de disciplina. Alguns professores, nostalgicamente, gostariam de voltar aos tempos de outrora, em que havia respeito garantido ao professor. Desse modo, o processo de referenciação dos termos linguísticos, ligado fortemente às situações concretas vivenciadas pelos sujeitos, aponta a um movimento dinâmico e tenso, vinculado à possibilidade de reprodução, de reformulação e de transformação dos sentidos.

\section{CONDIÇÕES DA ANÁLISE}

A análise direcionou-se pelas seguintes questões norteadoras: Que efeitos de sentidos se vinculam ao emprego de termos tais como disciplina, respeito, interesse em sala de aula, nas condições de estagiário e de professor de português na escola? Que caminhos para a formação do professor suscitam esses efeitos de sentidos analisados? A respeito do corpus analítico, cujo modo de constituição também faz parte do movimento de análise discursiva, trazemos, ainda, algumas especificações. No que se refere ao estagiário, o corpus se vincula ao arquivo de documentos relativos à disciplina de Prática de Ensino em Português, compreendendo ao todo oito semestres consecutivos em que foi ministrada. Incluem-se os relatórios do estágio e artigos escritos com base na experiência. Essa escrita resultou do objetivo 
de estimular o sujeito-estagiário de Letras a produzir sentidos seus sobre ser professor, na autoria de seus textos. $^{3}$

A condição de produção de sentidos pelos estagiários é peculiar, pois os coloca numa situação de balanço. Emitem julgamentos sobre a atuação dos professores pelos quais passaram em sua vida escolar e acadêmica, à medida que tecem ponderações sobre as suas próprias condições de assumir a regência de classe. Evocam não somente os conhecimentos dos campos específicos e aplicados de que dispõem, mas também como foi o processo de apropriação desses campos. Quanto a esse aspecto, cabe lembrar a condição de incompletude de qualquer currículo e da natureza lacunar, heterogênea e singular pela qual se compreende, como modo de subjetivação, uma formação profissional.

Inseridos nas práticas discursivas da universidade, os acadêmicos vão constituindo uma identidade como profissionais da área de Letras, por meio de filiações discursivas, mediadas pelas interlocuções no ambiente acadêmico formal e outros espaços educacionais complementares. Vão assumindo identidade como professores de português e literatura e, para isso, concorrem sentidos diversos produzidos que caracterizam a historicidade de sua constituição subjetiva.

A condição de professor, assim como também a de estagiário, neste estudo, circunscrevem-se unicamente aos dois contextos distintos indicados, sem pretensão de universalidade. Quanto a sua constituição, o corpus engloba tanto os recortes discursivos extraídos das produções textuais dos sujeitos-estagiários quanto os recortes discursivos referentes aos pronunciamentos em entrevista dos sujeitos-professores. Estes últimos apontam às entrevistas concedidas à doutoranda Cláudia Negreiros, durante 2011 e 2012, reunidas num documento de 180 páginas (NEGREIROS, 2011), para registro da pesquisa de campo de sua tese em andamento. Desse extenso material foram extraídos os recortes discursivos condizentes ao objetivo deste artigo.

Como condições de produção do discurso manifestado pelo sujeito-professor, referimo-nos a aspectos de caracterização dos profissionais participantes das entrevistas, bem como das escolas onde atuam e do sistema de ensino onde se enquadram. Conforme indica Negreiros (2011), em seu projeto de tese, os professores a serem entrevistados - e que efetivamente o foram - estavam atuando efetivamente nas escolas do sistema estadual pertencentes ao Município, na área de Linguagens. Algumas dessas escolas estão situadas na zona urbana e outras são mais afastadas. Os professores lecionam no Ensino Fundamental regular, de $5^{\mathrm{a}}$ a $8^{\mathrm{a}}$ séries, e no Ensino Médio; alguns atuam também na Educação de Jovens e Adultos. Atendem às turmas nos turnos manhã, tarde ou noite. No presente estudo, não objetivamos especificamente contemplar essas diferenças na análise, embora apareça nos recortes algum tipo de menção a elas. Além de língua portuguesa, em alguns casos os professores lecionam também línguas estrangeiras (inglês ou espanhol). Quanto à situação funcional, alguns são professores efetivos e outros contratados, o que implica diferenças em relação às condições de trabalho, tais como carga horária, lotação e salário.

Os professores possuem a devida titulação para lecionar a disciplina curricular pela qual são responsáveis; além da licenciatura em Letras ou de outros cursos de formação equivalentes, alguns detêm também titulação de nível médio para o magistério. A lotação nas escolas atendeu às necessidades locais e, ainda, não é incomum que tenham escolhido o magistério porque era a profissão possível naquele contexto. O trabalho na escola propiciou a alguns professores a participação em cursos específicos para a obtenção da devida titulação. As escolas contam com programas voltados à formação continuada dos professores, com intensiva participação dos professores. Encontram-se escolas instaladas em prédios novos, modernos. Nas longas entrevistas concedidas, a partir de roteiro de questões semiestruturadas, muitos retomaram a história da sua formação, entrelaçando docência e vida. Os professores têm experiência profissional significativa, falam com desenvoltura e segurança sobre o ensino ministrado; alguns ocupam ou ocuparam posições de gestão, como diretores de escola e coordenadores pedagógicos. Destaca-se o forte vínculo com suas comunidades e o sentido de politização. O envolvimento com os alunos, os projetos da escola, os colegas, as famílias manifesta-se com força.

Foi a partir desse corpus de entrevistas que este estudo passou a enfatizar o deslizamento da palavra indisciplina para as outras menções afins já indicadas, tais como interesse, respeito, querer estudar. A produção de sentidos efetivada em entrevistas orais, como é o caso do professor, difere da produção de textos escritos, como é o caso do estagiário; entretanto, de acordo com o enfoque discursivo, adotado nesta pesquisa, a diferença entre oral e escrito não é relevante.

\section{APresentaÇÃo da ANÁlise}

A apresentação da análise, a seguir, considera tanto as formulações do sujeito-estagiário quanto as do sujeito-professor, demarcando quando necessário alguns distanciamentos e aproximações. As formulações dos sujeitos são destacadas e numeradas, sendo acompanhadas dos sentidos analíticos correspondentes. Os efeitos de sentidos suscitados estão destacados nos títulos. 


\section{Efeito de sentido: definir disciplina confrontando posições}

A formulação seguinte concerne ao sujeito-estagiário, no seu texto:

[...] a disciplina a que me refiro não é aquela de todos estarem sentados, bonitinhos, quietinhos, ouvindo a professora, aquela em que o aluno não pode abrir a boca [...] não quer dizer que a aula seja um silêncio, um lugar em que o aluno não possa nem piscar.

Observa-se a busca por uma outra definição de disciplina. Por meio da negação de comportamentos ligados ao sentido tradicional da palavra, é defendida uma posição pedagógica de maior participação do aluno. A palavra disciplina aparece relativizada pela restritiva "a que me refiro", indicando uma posição pedagógica que não aceita o aluno submetido a ouvir sem manifestar-se. Essa outra posição é referida como "aquela", ou seja, por meio de um pronome demonstrativo de terceira pessoa que representa um afastamento do sujeito que enuncia: a disciplina indicada como aquela é outra e não esta próxima de quem enuncia; o afastamento se reforça com a negação explícita: "não é aquela".

Alunos quietinhos e calados não seria o seu desejo; consente que os alunos conversem e que levantem de suas cadeiras; aceita não ter a audiência de todos sempre; o uso dos diminutivos - "bonitinhos", "quietinhos" - aponta para algo que julga completamente fora do alcance do professor de hoje. $\mathrm{O}$ fato de nomear os sentidos da posição refutada significa que os reconhece e que caberá ao professor demarcar os limites, pois nem tudo vai ser permitido.

Essa tensão de controlar o que o aluno poderá ou não fazer em aula é um fato com o qual aceita conviver na sala de aula, endossando a posição de que cabe ao professor estabelecer os limites e aceitar a tensão de vigilância para que sejam respeitados. Seriam condições de disciplina que acha justas e possíveis, reforçando a posição de que os modos coercitivos de manter a disciplina, usados pelos antigos mestres, não valem mais para os dias de hoje. Defende a necessidade de estabelecer limites compatíveis com a realidade da sala de aula, dos alunos que a escola atual recebe, portanto, limites condizentes com as diferenças dos alunos e dos contextos sociais e culturais onde está inserida a escola.

Vêm à memória os meios aceitos outrora, até cerca de metade do século passado, para o professor manter a disciplina na turma; o próprio dicionário registra disciplina e disciplinar como ligadas a castigar. Disciplina ocorreria sob ameaça de castigo, não seria uma disposição voluntária. Mas nem o estagiário nem, algumas vezes, o professor ousariam aplicar castigos, como no tempo da palmatória dos antigos mestres. O estagiário verbaliza apenas os exageros de rigor (silêncio, nem piscar, não poder abrir a boca) como aquela outra disciplina que não é a que ele defende. Sugere, porém, certa nostalgia por não poder ter seus alunos todos sentados, bonitinhos, quietinhos, ouvindo o professor. Não seria esse um sonho secreto?

\section{Efeito de sentido: desejo de silêncio}

A idealização do aluno em silêncio ainda faz parte do imaginário do professor, como também aparece na seguinte formulação, esta agora do sujeito-professor, em sua entrevista:

(2) Doutoranda: Parece que é apaixonante a Educação de Jovens e Adultos.

Professora: É, porque é diferente, e a gente vê que era um pouco abandonado e quando você começa a trabalhar, a pessoa chega e eles querem estudar. Hoje, na escola, aqui na escola, tem muitas dificuldades com os adolescentes, mas nós temos uma escola, [...] com 250 alunos, todo o mundo é adulto, você chega lá às $8 \mathrm{~h}$ da noite e nem parece que tem aluno dentro da escola, é um silêncio. Eles querem é estudar. Então, é maravilhoso.

O fato de querer estudar está relacionado ao silêncio do aluno, representando reforço aos sentidos de enunciados cristalizados como: querer é poder, força de vontade. O querer do aluno é fruto das relações imaginárias, segundo Pêcheux (1993), que o professor assume a partir de seu lugar.

Em (3), a menção ao querer se reproduz, de um modo em que o querer da professora incidiria na modificação do não querer atribuído aos alunos. Falando de quais seriam as suas perspectivas em relação à profissão, assim se pronuncia:

(3) Ah... eu gostaria que houvesse uma grande mudança assim, no sentido de o aluno também querer, né. Muitas vezes a gente percebe que eles já vêm desmotivados para a sala de aula. A gente assim tenta de tudo quanto é jeito trazer algo diferente, mostrar o que ele vai ter de bom lá quando ele for procurar um emprego na sociedade...

Ela critica a perda de oportunidade de crescer via estudo, no aluno, justificando a rejeição à escola simplesmente porque ele não quer, não compartilhando com o professor igual querer. O não querer, a seguir, agrava-se, mostrando-se a indignação do professor:

(3) Aqueles jovens que realmente eles realmente não querem, não pensam no futuro, eles não permanecem de jeito nenhum na escola. [...] então eles vêm, mas não querem nada com nada [...]. E também tem aqueles que realmente eles nem entram no portão da escola, eles já ficam do lado de fora. 


\section{Efeito de sentido: alunos tão desinteressados que...}

O não querer está ligado ao desinteresse extremado atribuído ao aluno, como aparece a seguir, situando problemas graves de fora da escola, mas que o professor vê e sente, consternado, no dia a dia da escola e da sala de aula:

(4) [...] nós estamos com muitos alunos e alunas, já que eu falei, tão desinteressados que alguns, a gente não prova nada, mas alguns parece que são usuários de drogas, de bebida alcoólica, ... é, prostituição [...] Então, isso dificulta porque eles não estão conscientes do que é ficar em sala de aula, do que é trabalhar.

Para além de dificultar o trabalho em sala de aula, casos como esse, dos quais o sujeito não pretendia falar, mas fala ("já que eu falei", "a gente não prova nada"), soa como uma denúncia, desejo de que fosse tomada alguma providência. Esses comportamentos apelam a algum tipo de socorro a esses jovens, além de mera repressão a esses comportamentos, medidas essas que seriam concretizadas por outras instituições sociais. De que modo a escola, os professores de sala de aula, que veem e sofrem com essas situações, poderiam lidar com tais problemas?

\section{Efeito de sentido de desinteresse como desvalorização do trabalho do professor}

O sentido de desinteresse retorna com sentido distinto, na formulação do sujeito-professor, em resposta ao que mais dificultava o seu trabalho, conforme se segue:

(5) O que dificulta é... como sempre, o desinteresse; às vezes, o aluno, por eu trabalhar só com o terceiro ano (EM), eu recebia os alunos... às vezes até falavam assim: "não sei como que eu passei!". E eu sempre avaliei, tá. Eu sou meio que assim coronel nisso. Trabalhava com avaliação, sabe. De vários tipos, mas tinha avaliação. Ele sabia de onde que saía a nota dele.

Nesse caso, observa-se que o aluno participou das aulas e conseguiu sucesso; o desinteresse se dá em relação à falta do reconhecimento do aluno à dedicação do professor, ampliando o sentido de frustração do professor, que se mostra recorrente, quando diz: "como sempre". Aqui se torna problemático o anonimato do papel do professor para que o aluno crescesse.

\section{Efeito de sentido: o interesse depende do apoio da família}

A atribuição da causa do desinteresse dos alunos à família, de escola localizada em "um bairro mais afastado", suscita o sentido de que o professor deve assumir uma outra parte para compensar o problema. O trabalho de aproximação entre escola e família se destaca.
(6) Então, nós recebemos alunos que nem sempre vêm preparados pela família, apoiados, que estão interessados realmente em estudar [...] Alguns pais saem de madrugada e os filhos ficam em casa. Aí nos temos que trabalhar também essa parte familiar, essa parte até às vezes psicológica, uma parte religiosa mais acentuada, aquilo que às vezes a família fica por não fazer.

\section{Efeito de sentido: o sistema favorece a não ter interesse}

(7) Olha, a maioria deles não tem interesse de aprender, infelizmente. [...] eles trabalham, vêm da fazenda, e a maioria deles não apresenta assim ... interesse em estudar. Então o sistema realmente não ajuda nesse sentido, de mostrar interesse... aquele sistema que não reprova, eles já sabem disso, né. [...] porque infelizmente tem que ter assim uma forma de punir para eles terem interesse.

A aprovação/reprovação está arraigada no imaginário sobre a escola. Uma escola que não reprova não estimula o interesse do aluno; nesse o interesse não resiste diante da necessidade de trabalhar na fazenda, como se posiciona o professor.

\section{Efeito de sentido de indisciplina: falta de interesse, de respeito, não querem fazer nada}

As mudanças em relação à escola ampliam os problemas classificados como de disciplina, traduzidos como falta de interesse, de respeito e de querer estudar.

(8) Olha, o que dificulta o meu trabalho hoje em dia, que faz mais de 20 anos que eu dou aula, é a questão da indisciplina deles. Nossa, a indisciplina, 15 anos atrás a gente ... hoje é uma diferença muito grande. Uma falta de respeito, tem muitos alunos que têm falta de interesse. Então, você tenta mudar o seu método, tenta ... Eu fico agoniada quando vejo que eles não querem saber de ler os textos, não querem copiar o conteúdo, não querem saber de fazer nada. Então isso me deixa angustiada.

Nesse recorte o sujeito especifica o sentido de indisciplina como falta das condições de realizar o seu ensino como o desejaria. O manejo de uma classe com problemas de disciplina angustia o professor.

\section{Efeito de sentido de choque com os pais}

(9) Não, o meu filho não é assim. Então a gente mostra como o seu filho é assim. A gente chama o pai para ele ajudar, acompanhando os filhos, para o filho dele ter um futuro melhor. Então ele vem e fica do lado do filho. [...] os pais estão desvalorizando o professor [...]. [...] Tem que respeitar o professor! 
O sujeito mostra que o comportamento discrepante dos pais em relação ao professor é um fator de perpetuação da falta de respeito, pois a sociedade não está valorizando o trabalho do professor:

(10) É como se o professor fosse inimigo [...] então o que você ouve, às vezes, dos alunos é: Ah, minha mãe disse que se você fizer isso vai processar, e não sei o quê. Então, a situação ta muito, muito solta ... até para os pais está muito, né ... dialogar [...]

\section{Efeito de sentido de disciplina como necessária}

Na posição de professor-estagiário, especialmente, surge o temor de que os alunos não deixem o professor falar. É o que aparece na seguinte formulação:

(11) a sala de aula não pode ser uma loucura, gritos, empurrões, desrespeitos com os professores e colegas [...] é necessário que haja uma disciplina.

O sujeito posiciona-se a favor da necessidade de haver "uma disciplina". Reformula o significado da palavra através do indefinido uma, comprovando que há sentidos diversos abrigados pela palavra disciplina. Propõe que é preciso definir o que se entende por disciplina, embora o sentido de "uma" indique o movimento de busca, não o de certeza. Disciplina não tem sentido pronto. Causa-lhe perplexidade a falta das mínimas condições de ocupar o lugar de fala na sala de aula, que lhe seria de direito. Dá-se conta de que esse lugar de fala não lhe está garantido, que precisa ser batalhado... Uma loucura é como designa a classe na qual não há nenhuma disciplina.

Já na formulação a seguir, é reforçada a posição de necessidade de haver uma disciplina. Retomando enunciados discursivos do campo da educação, enuncia do lugar de professor-educador, responsável pelo aluno no sentido educacional amplo. Nesse sentido, o cerceamento pelo professor das manifestações discrepantes dos alunos justificar-se-ia pelo próprio bem deles.

(12) a disciplina em sala de aula deve ser para contribuir para o aprendizado do aluno, tanto em termos de conteúdo, de cultura como para ele como ser humano.

Assim, o sujeito-estagiário assume a condição de responsável por manter a disciplina em sala de aula, à medida que assume o papel de professor. Ser professor é deparar-se sempre com a questão da disciplina e buscar resolver os eventuais problemas. Entretanto, não está dito que queira ou saiba lidar com o confronto, com a repressão aos comportamentos discrepantes, ou pelo menos fica na esperança que isso não ocorra.

\section{Efeito de sentido de suportar a reação à colocação de limites}

A formulação a seguir mostra a situação de revide enfrentado pelo sujeito-estagiário, por ter posto e cobrado limites:

(13) Nesse dia, houve um problema de indisciplina - duas alunas saíram da aula mais cedo, sem permissão. Comuniquei o fato à vice-diretora, que conversou com as meninas no mesmo dia. Elas se mostraram indiferentes à conversa e começaram a me tratar de uma forma diferente, como se eu fosse uma ameaça para elas.

Esse sentido apareceu na posição de professor efetivo da classe, conforme (9) e (10). Lidar com o confronto faz parte da colocação de limites, conforme Outeiral (2000), salientando que o professor não escapa de conviver com essa tensão. A questão da transgressão dos limites pelos alunos na sala de aula, em suas inúmeras modalidades, dentre as quais sair da aula sem permissão, nem sempre é uma agressão dirigida ao professor, como profissional ou como pessoa. $\mathrm{O}$ desacato às normas estabelecidas na escola, designado como indisciplina, muitas vezes merece um tratamento diferente de uma simples repreensão, "conversa com a vice-diretora" ou outros tipos de punição convencionados na escola.

Estão por detrás da indisciplina, às vezes, situações de risco pelas quais passam os estudantes, impasses que estão atravessando em sua vida particular que geram ansiedade, agressividade e verdadeira impossibilidade de acompanhar as atividades de forma satisfatória e cumprir as normas, como foi indicado também nas formulações (3) e (4). Os alunos também podem usar a indisciplina para atrair a atenção do professor sobre eles e as dificuldades que os absorvem. Pode ser que um comportamento discrepante dirija-se a testar a autoridade do professor. Quando o sujeito-estagiário diz, em (13), que as alunas passaram a vê-lo como uma ameaça, poderia apontar, talvez, para a descrença de que o professor seria capaz de compreendê-las.

\section{Efeito de sentido: o respeito é uma conquista}

A interlocução entre o estagiário e os alunos, às vezes, é dificultada pelo impacto que causam as diferenças culturais entre ambos. Estas podem manifestar-se na aparência física, na linguagem, no tratamento pessoal; bastam pequenos detalhes ou gestos para que o distanciamento ou o entrosamento se estabeleça. $\mathrm{Na}$ formulação a seguir, o sujeito indica que o caminho para conseguir respeito requer grande abertura e dedicação da parte do professor para: 
(14) $[. .$.$] quebrar barreiras e jogar fora preconceitos, subs-$ tituindo-os pela criatividade e amor (no geral, esquecido por professores e alunos) são os passos iniciais para melhorarmos nossas aulas de português, tornando-as realmente importantes e respeitadas, como devem ser, tanto pelos alunos como pela sociedade em geral.

Atribui ao professor o trabalho de ser criativo e ao mesmo tempo amoroso, para quebrar as barreiras que causam a desvalorização com que alunos, professores e a sociedade estão tratando o aprender e o ensinar português; coloca-se na posição de denunciante de um grande equívoco que as pessoas não estão percebendo. Certamente é frustrante, para o estagiário, constatar que os alunos parecem não gostar do campo de conhecimentos de que ele gosta, que escolheu, para o qual se preparou.

O propósito claro de passar ao aluno o forte vínculo que possui com a área do conhecimento que ensina, a literatura, favorece a construção do respeito e admiração pelo aluno; essa valorização repercute na obtenção de "um pouco mais de domínio da sala", como se constata na formulação (15) do sujeito-professor:

(15) Deixei bem claro que a literatura pode transformar a vida tanto social como psicológica de uma pessoa [...] se não fosse o estudo literário, eu não seria hoje um professor um pouco mais esclarecido, tenho um pouco mais de domínio da sala [...]

Para tanto, o professor reforça a posição de que é preciso seduzir o aluno para o conhecimento, dando o exemplo, e isso representa uma conquista.

\section{Efeito de sentido: uma disciplina condizente com a proposta pedagógica}

Não é comum de imediato assumir que é necessário ao professor um encontro humano, o estabelecimento de um ponto de contato que represente sintonia com o aluno. Foi indicada para tanto, em (14) a necessidade de "criatividade", o afeto, a disposição para aceitar o outro, e para isso é preciso "quebrar barreiras". "Quebrar barreiras" seria dotar de flexibilidade o sentido tradicional de disciplina, buscando compreender que a exigência de disciplina dos alunos se altera conforme a proposta pedagógica do professor. O sentido de disciplina varia de acordo com a proposta pedagógica que o professor assume, como aparece na formulação a seguir:

(16) Não que eu esteja aqui fazendo uma "apologia da bagunça", mas dentro de uma proposta como a pedagogia de projetos, como o trabalho se desenvolve mais próximo do discurso polêmico que do autoritário, deve haver uma mudança na concepção de disciplina. Numa ação educativa que aceite a presença da alegria na escola, onde o lúdico, a criação, o entusiasmo e o engajamento sejam valorizados, a disciplina precisa ser vista de forma diferente.
O sujeito-estagiário retoma o discurso acadêmico no qual se constituiu para refletir sobre a questão da disciplina. Foram vivenciados problemas referentes ao que poderia ser chamado de ${ }^{4}$ falta de disciplina dos alunos na escola, mas, aprofundando a reflexão, constatou que o próprio referencial da prática de ensino possibilitaria compreender a necessidade de alargar o sentido de disciplina.

\section{Efeito de sentido de reflexão sobre as causas da indisciplina}

$\mathrm{Na}$ formulação (17), aparece uma reflexão sobre a resistência dos alunos à disciplina tradicional nos dias de hoje:

(17) Uma disciplina que se esgote nos limites da sala de aula e que dependa sempre da utilização de instrumentos de controle (geralmente punitivos) exteriores, certamente, não pode dar conta das demandas geradas (ou apenas despertadas?) não só pela pedagogia de projetos, mas pela própria realidade contemporânea presente fora dos muros escolares (ou até mesmo dentro: nos recreios, nos banheiros, no refeitório).

O sujeito-estagiário se posiciona contra a disciplina que se restringe aos limites da sala de aula, sem consideração das discrepâncias em relação ao que ocorre na sociedade e mesmo em outros lugares da escola. Mesmo dentro da escola a violência pode ocorrer. Compreende que a adoção de uma metodologia de ensino que canalize as energias para a participação do aluno nas atividades propostas minimize a necessidade de controle exagerado ou repressão.

O sujeito-estagiário deseja resguardar-se do papel de reprimir o aluno, pois luta pelo engajamento do aluno em sua proposta de ensino. Deseja conciliar, sem coibição, que o professor viabilize o seu trabalho de ensinar e o aluno o de aprender; o principal objetivo é que o aluno mostre que se engajou no trabalho proposto.

\section{Efeito de sentido de resolver o problema a seu modo}

Na formulação (18), o estagiário prepara-se para lidar com os enfrentamentos a que seria submetido para obter a disciplina necessária para dar as suas aulas no estágio. Prepara-se, sabendo que a turma irá testá-lo. O estagiário reforça o sentido de disciplina como respeito à autoridade do professor, como uma condição primeira para ensinar e aprender. Fala em "impor-se" frente à turma, avisando que ele iria controlar e punir se julgasse necessário; considera essa capacidade como pré-requisito para ser professor; não se referindo, como apareceu em (17), a uma vinculação direta entre disciplina e metodologia adotada. Mostra abertamente sua disposição para obter disciplina na classe: 
(18) Ao assistir a minha primeira aula no colégio, na cadeira de Prática de Ensino, fiquei me questionando como manteria a disciplina. O professor regente de português tinha um método muito bom. Quando um aluno estava conversando, ele o chamava pelo nome. $\mathrm{Na}$ mesma hora, o aluno se calava. Imaginei: "como que eu vou fazer isso?" Primeiro, não sabia o nome deles, segundo, eu não seria realmente o professor titular.

O sujeito procura o seu próprio modo de resolver o problema. Baseou-se na experiência de observação prévia das aulas do professor titular da classe, mas verificou que não poderia usar o mesmo recurso. Com senso de humor, emprega o discurso direto:

\section{Efeito de sentido de colocar os limites abertamente}

(19) Pensei em encarnar o tipo ditador, aquele que entra na sala e diz: não quero barulho (conversa). Não deixo ninguém ir ao banheiro. Caso alguém me desrespeitar é rua e pronto. Após, pensei em encarnar o tipo bonzinho. Aquele que faz tudo para agradar ao aluno, traz balas, chocolates, satisfaz todas as vontades dos alunos. Se vê algum aluno com a cara fechada pergunta o que está havendo, querendo intrometer-se na vida pessoal do aluno.

O estagiário mostra que aceitou submeter-se à prova de manter a disciplina em sua classe, no estágio, ficando satisfeito com os resultados que conseguiu; vencida a prova, disciplina não lhe parece mais tão alarmante, é vista agora como algo que dá para resolver. Aderiu ao sentido de que é o professor que conduz o padrão de disciplina que espera, cabendo-lhe o controle, a vigilância. Na formulação (20), conclui:

(20) Deveria ser eu mesmo para manter a disciplina. Impor limites aos alunos e respeitá-los.

Observa-se esse enunciado discursivo na formulação (21), do professor efetivo na escola:

(21) Eu gosto muito de ser professor, de passar experiências, e gosto muito de ser professor da maneira que eu sou [ ...] de ir para a escola, de estudar bastante, e procurar sempre, de estar sempre preparado para o conteúdo que eu vou trabalhar, mas também não gosto de ficar sozinho na frente. Eu sou muito de estar falando, e parar e já trazer alguém para a frente para falar junto comigo, misturar um pouco. Então, eu não tenho problema de disciplina nas minhas aulas, né. Por quê? Porque a minha sala é sempre eu e toda a turma, né.

O professor experiente põe em prática diariamente o sentido de ser "eu mesmo" diante da turma, apontando à identidade profissional que assume: a de um professor que se prepara para dar boas aulas, incentivando a interlocução com os alunos a partir da qual a aula passa a ser de ambos, não só do professor mas também dos alunos. Alguns professores demonstram mais facilidade, e até habilidade, para encontrar o seu próprio caminho, como indicado em (21), por exemplo, do qual faz parte saber manter o interesse, o respeito, o domínio da sala, enfim, "uma" disciplina, de um modo em que ele e os alunos tenham certa cumplicidade em suas diferentes posições ocupadas. Em (22), o professor mostra como tornou a atividade de ensinar na sala de aula prazerosa.

\section{Efeito de sentido: aprender a cada experiência}

(23) Eu nunca tive problema com aluno [....] no fundo, eu, graças a Deus, sou respeitado, meus alunos me respeitam, meus colegas me respeitam [...] Quando eu entro na sala de aula, eu posso estar doente, eu posso estar do jeito que for... os meus colegas saem tudo descabelado: que esse diabo, esse capeta... eu, não, eu brinco com eles, sim, mas é bom pra mim, você está entendendo? Eles falam que a minha terapia é brincar com os meus alunos, isso aí. [...]. O que dá certo é quando... você vai trabalhar, agora não porque eu estou mais veterano, mas no começo eu estranhava um pouco... sei lá, pelo menos eu acho, é quando os alunos começam a olhar para mim e quando eu vejo que eles estão começando a compreender. Aí eu noto que eles têm a psicologia do aluno, e tem a do professor. Quando até aquele bagunceiro começa a falar assim pra você [gesto de olhar fixo, imitando o aluno]. Aí você fala: está dando resultado, é uma coisa que está dando certo.

Destaca-se a importância do afeto, do magistério como uma profissão humana, na qual é preciso voltarse intensamente para o outro. $\mathrm{O}$ trabalho pedagógico na sala de aula está atravessado pelo desejo de que os alunos gostem de seu trabalho, essa a é compensação, como está resumido em (23): "Gostam do meu trabalho. Gostam como professora. Eles gostam, é isso".

\section{À GUISA DE CONCLUSÃo}

Com base nas análises feitas, foram identificados efeitos de sentidos diferenciados. A palavra disciplina aponta a um sentido muito arraigado no discurso pedagógico. Ocupa lugar de destaque na memória discursiva não somente do sujeito-professor, mas de toda a sociedade, na qual está instituída a escolarização. As designações vinculadas à palavra disciplina foram enfocadas por meio da análise de formulações discursivas do sujeitoestagiário e do sujeito-professor experiente, mostrando efeitos de sentido que apresentam analogias e diferenças. 
Essa produção assinala o movimento de confronto de posições pedagógicas. Enunciar sobre disciplina, tanto nos textos escritos dos estagiários quanto nas entrevistas orais concedidas pelos professores, demandou que os sujeitos buscassem especificar o sentido em que a estavam empregando no seu processo de estabelecer um referente julgado adequado à sua significação. Desse modo, apareceram no fio do discurso palavras relacionadas, bastante recorrentes, tais como: interesse, desinteresse, respeito, domínio de turma, silêncio. Esse deslizamento de palavras empregadas representa a reformulação do discurso, necessária ao sujeito para dar sentido seu à questão da disciplina. Cada termo, ao ser empregado pelo sujeito que toma a palavra, significa diferentemente, de acordo com a historicidade determinante da enunciação dos sujeitos.

As questões sobre disciplina não estão fechadas. Não obstante, o estudo permitiu, dando a palavra aos sujeitos, um balanço a respeito de velhos e novos sentidos que concernem à realidade da sala de aula, ressaltando as complexas relações que compreende. Contribuindo à reflexão sobre a problemática da formação do professor, apontou à necessidade de não deixar apenas como subjacentes as questões ligadas à disciplina, sugerindo que o tema seja objetivado especificamente nos cursos de formação, tanto na licenciatura, quanto na formação continuada.

\section{REFERÊNCIAS}

AUTHIER-REVUZ, Jaqueline. Palavras incertas: as não-coincidências do dizer. Campinas: Editora da Unicamp, 1998.

AUTHIER-REVUZ, Jaqueline. Arrêts sur mots: l'épreuve de la langue dans l'énounciation et l'écriture. 2006. Mimeo.

AUTHIER-REVUZ, Jaqueline. Paradas sobre palavras: a língua em prova na enunciação e na escrita. Educação e Realidade, Porto Alegre, v. 36, n. 3, p. 651-679, 2011.

BHABHA, Homi K. O local da cultura. Belo Horizonte: Ed. UFMG, 1998.

DALLA ZEN, Maria Isabel H.; MUTTI, Regina Maria Varini. A prática de ensino de língua e literatura e a pedagogia de projetos. In: XAVIER, Maria Luiza M.; DALLA ZEN, Maria Isabel H. (Org.). Ensino de língua materna: para além da tradição. Porto Alegre: Mediação, 1998. p. 103-115.

DUBET, François. Quando o sociólogo quer saber o que é ser professor. Revista Brasileira de Educação, São Paulo, ANPed, n. 5 e n. 6,1997 , p. 222-231.

ERNST-PEREIRA, Aracy; MUTTI, Regina Maria Varini. $\mathrm{O}$ analista de discurso em formação: apontamentos à prática analítica. Educação \& Realidade, Porto Alegre, v. 36, n. 3, p. 817-833, 2011.

FERREIRA, Aurélio Buarque de Holanda. Novo dicionário século XXI: o dicionário da língua portuguesa. 3. ed. Rio de Janeiro: Nova Fronteira, 1999.
GUIMARÃES, Eduardo. Os limites do sentido: um estudo histórico e enunciativo da linguagem. Campinas: Pontes, 1995.

GUIMARÃES, Eduardo. Semântica do acontecimento: um estudo enunciativo da designação. Campinas: Pontes, 2002.

MUTTI, Regina Maria Varini. A prática de ensino em português. Projeto de pesquisa. Porto Alegre: Faculdade de Educação, UFRGS, 2000.

MUTTI, Regina Maria Varini. O primado do outro sobre o mesmo... SEAD - SEMINÁRIO DE ESTUDOS EM ANÁLISE DE DISCURSO, 1. Porto Alegre, Universidade Federal do Rio Grande do Sul, 2003a. 7 p. Anais... Disponível em: $<$ http:// www.ufrgs.br/analisedodiscurso/anaisdosead/>.

MUTTI, Regina Maria Varini. Reformulações do sentido de indisciplina no discurso pedagógico. ENCONTRO DO CELSUL, 5., Centro de Estudos Linguísticos do Sul. Curitiba, PR. Anais... 2003b.

MUTTI, Regina Maria Varini. Memória no discurso pedagógico. SEAD - SEMINÁRIO DE ESTUDOS EM ANÁLISE DE DISCURSO, 2., Porto Alegre, Universidade Federal do Rio Grande do Sul, 2005. 7 p. Anais... Disponível em: $<$ http://www. ufrgs.br/analisedodiscurso/anaisdosead/>.

NEGREIROS, Cláudia Landin. Entrevistas nas escolas: professores de língua portuguesa, coordenadores, diretores, secretários e assessor pedagógico. Anexo ao projeto de tese de doutorado: Sentidos sobre o ensino de língua portuguesa nas escolas estaduais em Barra do Bugres - MT: a prática docente em discurso. Porto Alegre: PPGEDU/UFRGS, 2011.

ORLANDI, Eni. P. Análise de discurso: princípios e procedimentos. Campinas: Pontes, 1999.

OUTEIRAL, José. Escola, limites e pós-modernidade. Vídeo da palestra proferida na FACED/UFRGS, Central de Produções, 2000.

PÊCHEUX, Michel. Semântica e discurso: uma crítica à afirmação do óbvio. Campinas: Editora da Unicamp, 1995.

PÊCHEUX, Michel. Análise automática do discurso (AAD69). Trad. por Eni Pulcinelli Orlandi. In: GADET, Françoise; HAK, Tony. (Org.). Por uma análise automática do discurso. Campinas, São Paulo: Ed. da Unicamp, 1997a. p. 61-161.

PÊCHEUX, Michel. A análise de discurso: três épocas. Trad. por J. A. Romualdo. In: GADET, Françoise; HAK, Tony. (Org.). Por uma análise automática do discurso. Campinas: Ed. da Unicamp, 1997a. p. 311-318.

PÊCHEUX, Michel. Discurso: estrutura ou acontecimento. Trad. por Eni P. Orlandi. Campinas: Pontes, 1997b.

PÊCHEUX, Michel. Papel da memória. In: ACHARD, Pierre et al. Papel da memória. Trad. por José Horta Nunes. Campinas: Pontes, 1999. p. 49-57.

SANTOS, Ema Dias dos. A pedagogia tradicional e a progressista em confronto. In: DALLA ZEN, Maria Isabel; SOUZA, Nádia G. (Org.). Práticas de ensino na UFRGS: narrando pedagogias. Porto Alegre: Editora da Universidade/ UFRGS, 2001.

\section{NOTAS}

${ }^{1}$ A análise referente aos estagiários foi apresentada parcialmente no Encontro Regional do Centro de Estudos Linguísticos do Sul - CELSUL, 
Curitiba, 2003; para este artigo, a análise foi atualizada, agregando-se novos elementos.

2 Pesquisa-ação: A prática de ensino em português, da qual este estudo retomou uma das análises referente à perspectiva dos estagiários, e Projeto de tese em Educação - PPGEDU/DINTER/UNEMAT/UFRGS, de autoria de Cláudia Landin Negreiros, de cujo corpus de entrevistas foram extraídos os recortes discursivos analisados, correspondentes à perspectiva do professor titulado.
3 Alguns desses artigos resultaram em publicações: Santos (2001), Dalla Zen e Mutti (1998), indicando ainda que no periódico Cadernos do Aplicação (UFRGS) foram publicados diversos textos de autoria dos estagiários.

${ }^{4}$ As formulações (16) e (17) foram extraídas de Santos 2001).

Artigo recebido em julho 2014

Aprovado em novembro 2014. 